\title{
Banana peel and mango kernel-based polymers and their suitability in enhanced oil recovery
}

\author{
Adesina Fadairo ${ }^{1,2} \cdot$ Gbadegesin Adeyemi $^{2} \cdot$ Ogunkunle Temitope $^{2} \cdot$ Ling Kegang $^{1} \cdot$ Rasouli Vamegh $^{1} \cdot$ \\ David Enuice $^{2} \cdot$ Ilusemiti Temitope $^{3} \cdot$ James Ayoo $^{4}$
}

Received: 2 November 2020 / Accepted: 7 March 2021 / Published online: 25 March 2021

(c) The Author(s) 2021

\begin{abstract}
This study reports the extraction and performance evaluation of two bio-derived polymers for enhanced oil recovery applications. The oil displacement processes were conducted using six (6) unconsolidated sandstone core plugs. Reservoir permeability tester was used to simulate real reservoir conditions in order to evaluate the suitability of the formulated biopolymers for oil displacement applications at laboratory conditions. The experimental results indicate the effectiveness of the biopolymer solutions in enhanced oil recovery in terms of their superior incremental oil recoveries after conventional waterflood with percentage oil recovery of 30.9-39.3\% for banana peel derived polymer and 40.6-50.8\% for mango kernel derived polymer compared to conventional waterflood with percentage recovery of $16.2-32 \%$ of the initial oil in place. This work identified the potential suitability and use of bio-derived polymers for enhanced oil recovery applications with emphasis on their biodegradability.
\end{abstract}

Keywords Banana peel ploymer $\cdot$ Mango kernel polymer $\cdot$ Enhanced oil recovery $\cdot$ Agro waste materials $\cdot$ Bio-syntheised polymer

\section{Abbreviations \\ MKP Mango kernel polymer \\ BPP Banana peel polymer}

\section{Introduction}

After primary and secondary recovery application, over sixty-seven percent of initially in-place oil is left in the hydrocarbon reservoir (Sarsenbekuly et al. 2017; Raffa et al. 2015; Green and Willhite 1998). As hydrocarbon reservoirs get matured, production from such reservoirs becomes challenging due to excessive production of unwanted fluid (water), which affects the recovery efficiencies (Fadairo et al. 2014 and Oladepo et al. 2017) and increases overall cost

Adesina Fadairo

adesinafadairo@yahoo.com

1 Department of Petroleum Engineering, University of North Dakota, Grand Forks, USA

2 Department of Petroleum Engineering, Covenant University, Ota, Nigeria

3 Schlumberger Nigeria Limited, Lagos, Nigeria

4 Chevron Nigeria Limited, Lekki, Nigeria in field development. Based on recent trends in the world energy demands, alongside apparent depletion of oilfield reservoirs, enhancing the recovery from existing assets is lucid bearing in mind that approximately two-third of initial oil in place is left in the porous media after conventional mechanism of hydrocarbon recovery (Ali et al. 2019; Sarsenbekuly et al. 2017). Much of these leftover oils (residual oil) can be further recovered using tertiary technologies. Generally, the target of enhanced oil recovery (EOR) for light oil is in excess of $40 \%$ of the initial oil in place, but much higher for recovery of heavy oils (Ali et al. 2019). Traditionally, water flooding is commonly adopted in the oil and gas industry to achieve better displacement efficiencies and equally maintaining sufficient hydrostatic pressure head within the reservoir (Ogunkunle et al. 2020). However, due to the heterogeneous nature of the hydrocarbon reservoir with varying permeability across different layers, channeling of excessive water via production from high permeability zones is always encountered. As a result, enormous amount of movable hydrocarbon is trapped behind the flood front during typical water flooding operation and results in poor sweep efficiency/overall recovery (Mishra et al. 2014; Fadairo et al. 2019). Therefore, to overcome this problem research focus had been on reducing the mobility of injected water during water flooding by addition of polymers (Sydansk 2007; 
Hatzignatiou et al. 2018; Hatzignatiou et al. 2016). Polymer flooding is a generally known as non-thermal chemical tertiary recovery method where a small quantity of heavy molecular weight water-soluble polymers augmented water injection to improve mobility and sweep efficiency of oil reservoirs. The intended function of the added polymer is to regulate the polymer solution's rheological properties, provide reduced mobility to water but better mobility ratio for the flooding process, stable oil-water-emulsion, improve displacement and control water channeling (Ali et al. 2019; Adewole and Muritala 2019). Polymer flooding performance is strongly controlled by various parameters such as reservoir temperature, salinity of the medium, crude oil properties and adsorption and polymer retention rate.

Permeability reduction is the common production challenge resulting from polymer entrapment, adsorption, hydrodynamic retention of polymers and precipitation owing to interactions of polymer with formation brine during polymer flooding (Lake et al. 2014). Despite these drawbacks, incremental oil recovery achieved with polymer flooding is attributed to augmentation of the conventional waterflood in which polymer addition helps the injected fluid to contact larger volume of the left-behind oil comparing to conventional waterflood (Riahinezhad et al. 2017a, b). Several investigations have been established on the suitability of polymers for improving the injectivity of injected water as well as modifying the properties of the polymer solution to annihilate the inherent challenges with the choice of polymer and polymer flooding performances. To solve the problem of poor thermos-stability and salt tolerance of existing water-soluble polymer at reservoir conditions, Sarsenbekuly et al. (2017) reported the interactions of a novel thermosviscosifying functional polymer for enhanced oil recovery under different salt concentration and temperature. In their studies, the thermal stability of different polymer concentrations was analyzed via the polymer rheological properties. It was reported that the polymer viscosities were initially smoothly decreased and then increased with increase in temperature. The formulated polymer solution showed better viscoelastic properties at low concentrations. Kumar and Mandal (2017) synthesized an anionic polymeric surfactant from Jatropha oil that plays a dual-purpose role in enhanced oil recovery. The polymeric surfactant was evaluated for its applications in enhanced oil recovery, and a good shear stability of the system was reported at high shear rate owing to its unique molecular weight. Pope (2007) emphasized the use of polymer flooding for fields with at least $200 \mathrm{cP}$ of crude oil viscosity because the polymer flooding implemented in the Daqing field exhibited a $12 \%$ increment in the oil production that is about 220,000 barrels per day increment and from the best commercial projects studied. There was a 1 STB increment per 1-2 dollars' investment in the field. Mishra, Bera and Mandal (2014) studied polymer adsorption impact on the decrease in effective permeability of oil and its recovery. Likewise increase in polymer concentrations yields more oil recoveries over time during flooding experiments. Hence, increase in the polymer concentration had a direct influence on the recovery. However, the choice of polymer was not cost-effective and high concentration led to plugging and increased polymer retention. Ali et al. (2019) reported the application of low-salinity polymericnanofluid for interfacial tension and wettability alteration of residual oil in carbonate reservoirs. The green nanofluid formulated with natural polymer mixed with low salinity water enabled higher recovery of oil from the carbonate reservoir with about $19.28 \%$ initial oil in place recovered. This was attributed to a significant reduction in interfacial tension between the aqueous solution and trapped oil, superior viscosity, good emulsion stability and wettability alteration from oil-wet towards a stronger water-wet rock with contact angle ranging from $137^{\circ}$ to $34^{\circ}$. Evaluation of the performance of a tailor-made water-soluble copolymer for enhanced oil recovery polymer flooding applications was discussed by Riahinezhad et al. (2017a). The study evaluated the performance of a tailor-made water-soluble copolymer via displacement test using unconsolidated sand-packs with simulated reservoir conditions. The results demonstrated the improved mobility control of the functionally formulated copolymers compared to conventional oilfield polymers. Although most of the reported literature on the modification of polymer properties to enhance their performance in enhanced oil recovery, the chemical nature of these polymers still poses greater challenge as the polymers are harmful and could corrode production equipment. Additionally, in this period of low crude oil price, application of high-cost conventional polymers in chemical enhanced oil recovery is not economically encouraging. Therefore, research focus is now on the synthesis of enhanced oil recovery polymers from natural materials for enhanced oil recovery applications. In the current study, bio-waste-derived polymers have been synthesized from banana and mango peels. The corresponding polymer solutions were characterized as a function of polymer concentration and shear rate to determine its enhanced oil recovery ability. The performance of the polymer solutions under core flooding conditions was analyzed using a reservoir permeability tester (RPT) (Fig. 3) to determine oil recovery suitability.

\section{Experimental}

\section{Materials}

Banana peel and mango seed wastes (mango seed kernel) were sourced from a local market in Nigeria. Analytical grade chemicals (hydrochloric acid and caustic soda) were 
supplied by Guanghzhou Jinghuada Chemical Reagents Co., Ltd., China. Representative core samples from Niger Delta oilfield sandstone reservoirs were obtained from an indigenous Marginal oilfield operator in Nigeria and were subsequently used in the enhanced oil recovery applications. The crude oil sample used was from the Niger Delta Nigeria. The oil sample exhibits density of $0.842 \mathrm{~g} / \mathrm{cm}^{3}$, viscosity of $2.5(\mathrm{cP})$, API gravity of 36.6 , flash point of $98.2^{\circ} \mathrm{C}$ and $\mathrm{pH}$ value of 9.11. Digital viscometer (DV-E) manufactured by Brookfield Ametek company USA was used to characterize the formulated polymer solutions viscosity as a function of concentration. The viscometer is equipped with 18 speeds for greater range capability $(0.3-100 \mathrm{rpm})$, accurate torque measurements with a precision of $1 \%$ of full-scale range and a digital display to ensure easy and accurate readout of test results for synchronized measurement of torque and viscosity in real-time.

\section{Methods}

\section{Polymer extraction}

Mango and banana are two of the most economic fruits. After consumption, a considerable amount of the peels and seeds is discarded as waste. Yet, most fruit seeds and peels

Table 1 Proximate composition of mango seed kernel and Banana peel (Torres-León et al. 2016; Anhwange et al. 2009)

\begin{tabular}{llcc}
\hline S/N & Parameter & Banana peel & Mango seed kernel \\
\hline 1 & Crude Protein (\%) & $0.9 \pm 0.3$ & $6.8 \pm 0.5$ \\
2 & Crude Lipid (\%) & $1.7 \pm 0.1$ & - \\
3 & Carbohydrate (\%) & $59.0 \pm 1.4$ & $76.84 \pm 0.22$ \\
5 & Crude Fiber (\%) & $21.7 \pm 0.25$ & $2.01 \pm 0.45$ \\
6 & Crude Fat (\%) & - & $2.20 \pm 0.05$ \\
7 & Moisture Content (\%) & $6.7 \pm 2.22$ & $9.14 \pm 0.05$ \\
8 & Ash (\%) & $8.5 \pm 1.52$ & $2.88 \pm 0.05$ \\
\hline
\end{tabular}

are of tremendous nutritional values because they host most of the essential nutrients (Table 1). This is why in this study, mango seed kernel and banana peel wastes are used as substrates for the extraction of polymers owing to their high carbohydrate content (Table 1). Six hundred grams (600 g) of mango seed kernels and banana peels were washed carefully with warm water to remove all alien materials, sliced, chopped and blended. Thereafter, deionized water was added into a beaker containing the pulps and allowed for few hours, and the extraction was done using a centrifuge at varying rpm (1000, 2000, 4000) according to Altemimi (2018) and Muazu et al. (2011). The centrifuged samples were filtered through a $180 \mu \mathrm{m}$ sieve. Thereafter, the filtrate was allowed to settle, and caustic soda was added to break the starch from its protein contents and equally to neutralize the remaining starch from being acidic. Deionized water was added several times to remove the excess caustic soda via washing process. The resulting wet starch was dried at room temperature for $6 \mathrm{~h}$, then pulverized into powdery form and then stored for later use (Fig. 1).

\section{Polymer modification}

Starch from banana peel and mango seed kernel is carbohydrate polymers such as every other polymer. They contain both the amylopectin (branched chains) and amylose (linear chains). The amyloses are the group responsible for gelation (viscosifiers), while the amylopectin serves as shield for the polymer solution, (Fadairo et al. 2019). Polymers for enhanced oil recovery are required to have better viscosity which implies less amount of the amylopectin group. Before the polymer solutions enhanced oil recovery applications, the extracted polymers were modified via acid hydrolysis to reduce the amylopectin (branched chains) contents of the polymer (Fig. 2) (Zhang et al. 2019; Singh et al. 2014). This improvement in viscosity was demonstrated with the difference in rheological behavior of the formulated polymer solutions before and after modification.
Fig. 1 Enhanced oil recovery target for light and heavy oil when water saturation is around $20 \%$ pore volume (Ali et al. 2019)
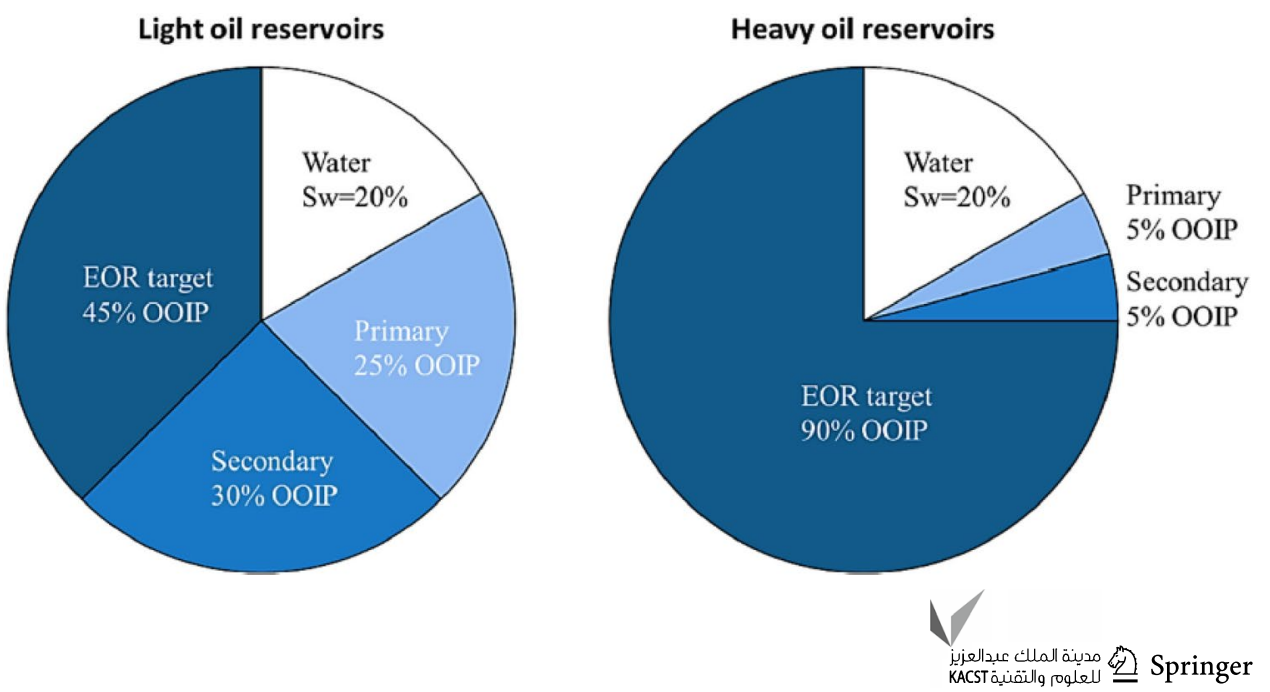


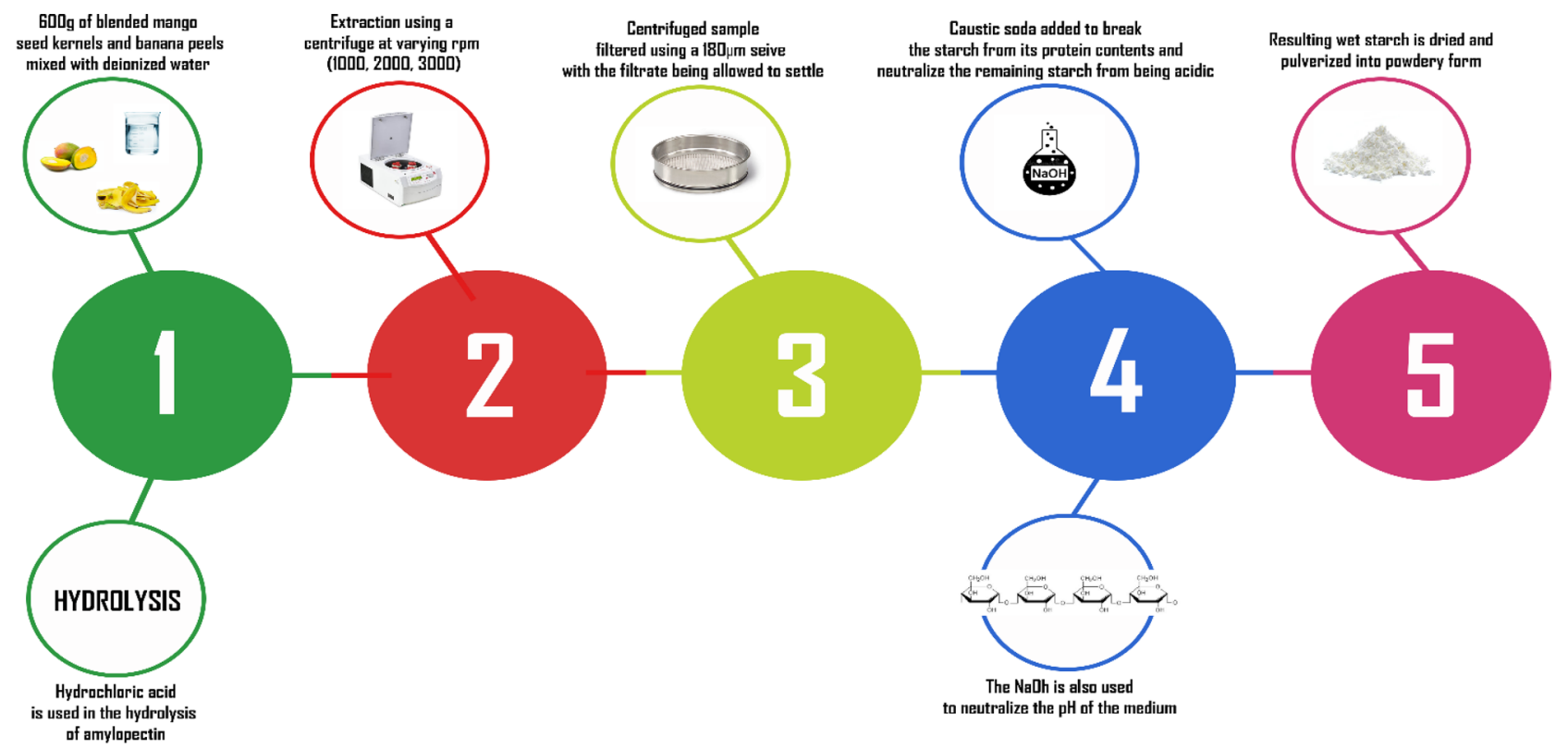

Fig. 2 Workflow for the polymer synthesis

\section{Coreflood arrangement}

To evaluate the suitability of the formulated polymers for enhanced oil recovery applications, core flooding experiment was carried out using Ofite reservoir permeability tester (Fig. 3). The core plugs were manually saturated with brine to initiate the process, then crude oil injected into the core samples at $1.5 \mathrm{cc} / \mathrm{min}$ until no brine production was observed in the effluent to restore the core samples to an initial saturation state. Then, waterflooding was done at the same conditions as the first recovery process to create the initial oil saturation state desired, afterwards

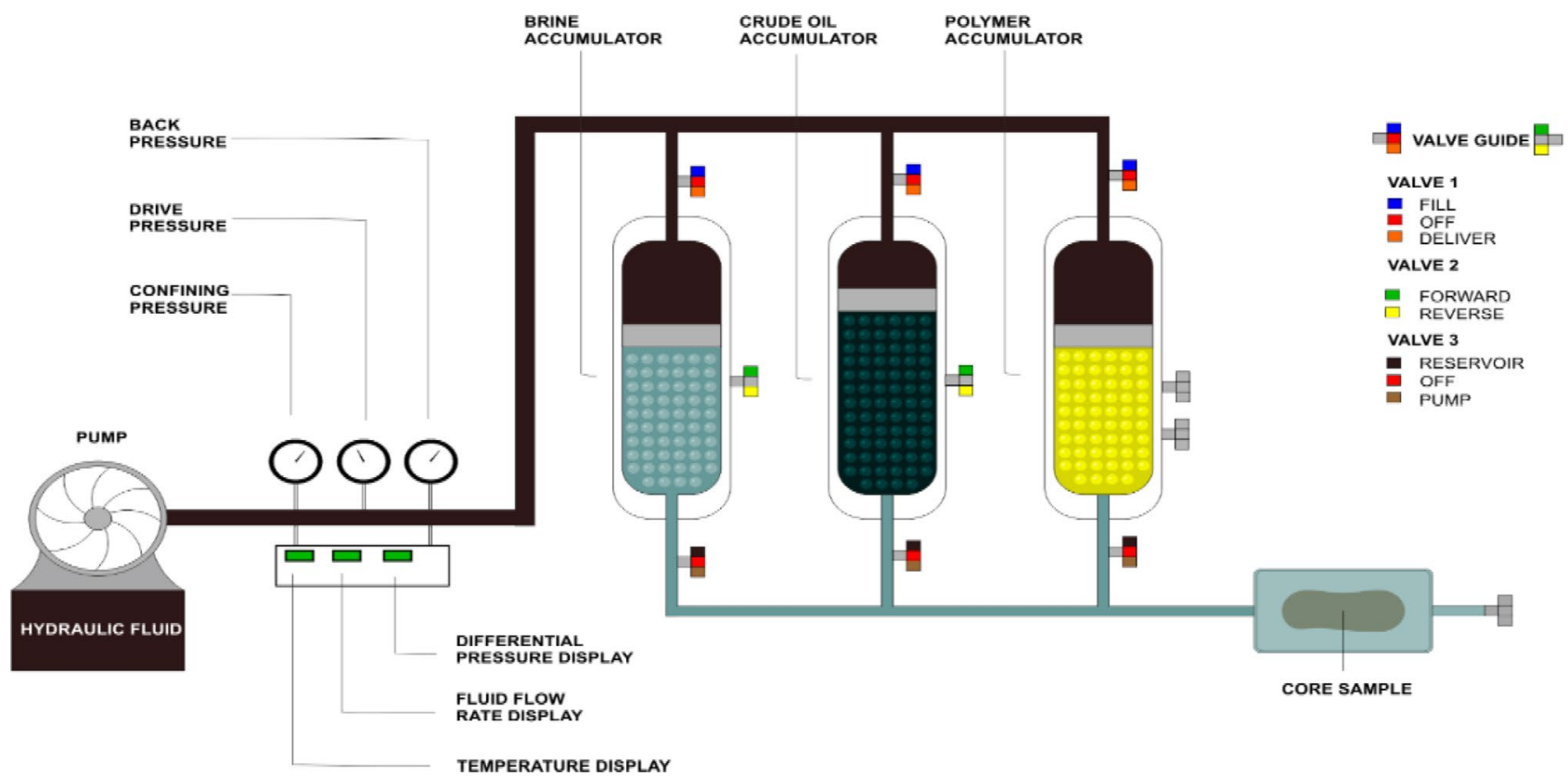

Fig. 3 Schematic of the core flood experimental setup using Ofite Reservoir Permeability Tester 
Table 2 Core samples petrophysical properties

\begin{tabular}{|c|c|c|c|c|c|c|c|c|}
\hline Core samples & Length (cm) & Diameter $(\mathrm{cm})$ & $\begin{array}{l}\text { Weight } \\
\text { dried (g) }\end{array}$ & $\begin{array}{l}\text { Weight satu- } \\
\text { rated }(\mathrm{g})\end{array}$ & $\begin{array}{l}\text { Bulk volume } \\
\left(\mathrm{cm}^{3}\right)\end{array}$ & $\begin{array}{l}\text { Pore volume } \\
\left(\mathrm{cm}^{3}\right)\end{array}$ & Porosity (\%) & $\begin{array}{l}\text { Perme- } \\
\text { ability } \\
(\mathrm{mD})\end{array}$ \\
\hline 1 & 6.7 & 3.5 & 108 & 125 & 64.5 & 17.9 & 28 & 192 \\
\hline 2 & 6.3 & 3.5 & 105 & 121 & 60.6 & 16.4 & 27 & 180 \\
\hline 3 & 6.8 & 3.6 & 119 & 138 & 69.2 & 19 & 27 & 184 \\
\hline 4 & 5.1 & 3.7 & 127 & 136 & 54.8 & 9 & 16 & 130 \\
\hline 5 & 3.4 & 3.6 & 48 & 59 & 34.6 & 10.9 & 31.4 & 92 \\
\hline 6 & 3.6 & 3.6 & 93 & 104 & 36.6 & 11.5 & 31.4 & 97 \\
\hline
\end{tabular}

Table 3 Polymer concentrations

\begin{tabular}{llll}
\hline Polymer source & $\begin{array}{l}\text { Polymer/ } \\
\text { distilled water } \\
\text { ratio }\end{array}$ & Polymer Conc & $\begin{array}{l}\text { Polymer } \\
\text { viscosity } \\
\text { (cP) }\end{array}$ \\
\hline Banana peels & $200 \mathrm{~g} / 400 \mathrm{ml}$ & 0.5 & 16.5 \\
& $160 \mathrm{~g} / 400 \mathrm{ml}$ & 0.4 & 13.8 \\
Mango kernel seeds & $120 \mathrm{~g} / 400 \mathrm{ml}$ & 0.3 & 12.5 \\
& $200 \mathrm{~g} / 400 \mathrm{ml}$ & 0.5 & 18.2 \\
& $160 \mathrm{~g} / 400 \mathrm{ml}$ & 0.4 & 15.6 \\
& $120 \mathrm{~g} / 400 \mathrm{ml}$ & 0.3 & 9.5 \\
\hline
\end{tabular}

various concentrations of the test fluids (different polymer concentrations) were injected at $3 \mathrm{cc} / \mathrm{min}$. All experiments were performed at ambient conditions $\left(27.6{ }^{\circ} \mathrm{C}, 1 \mathrm{Atm}\right)$.

\section{Results and discussion}

Table 2 below presents the petrophysical properties of the core samples used for this study. The average core sample permeability is around $145.8 \mathrm{mD}$ and porosity $26.8 \%$.
Three polymer concentrations were prepared from the polymers extracted from banana peel and mango kernel by dissolving the extracted polymers in distilled water as presented in Table 3. Overhead stirrer method was adopted for the polymer solution preparation according to API recommended practices for evaluation of polymers used in enhanced oil recovery applications.

\section{Rheological behavior}

To evaluate the extracted polymers as potential candidates for polymer flood applications, the rheological behavior of the polymers in solution was measured under different concentrations. Figures 4, 5, 6 permits the comparison of the crude oil sample and the polymer solutions to access the effects of shear rate and polymer concentrations on the viscosities of the polymer. Both the crude oil and the polymer solutions exhibit non-Newtonian flow behavior, this fluids behavior demonstrates a decrease in fluid viscosity as the shear rate increases. Generally, the polymers show an increase in solution viscosity with an increase in concentrations of the polymers. The mango kernel-derived polymer exhibited superior viscosities at different concentrations
Fig. 4 Rheogram of the crude sample

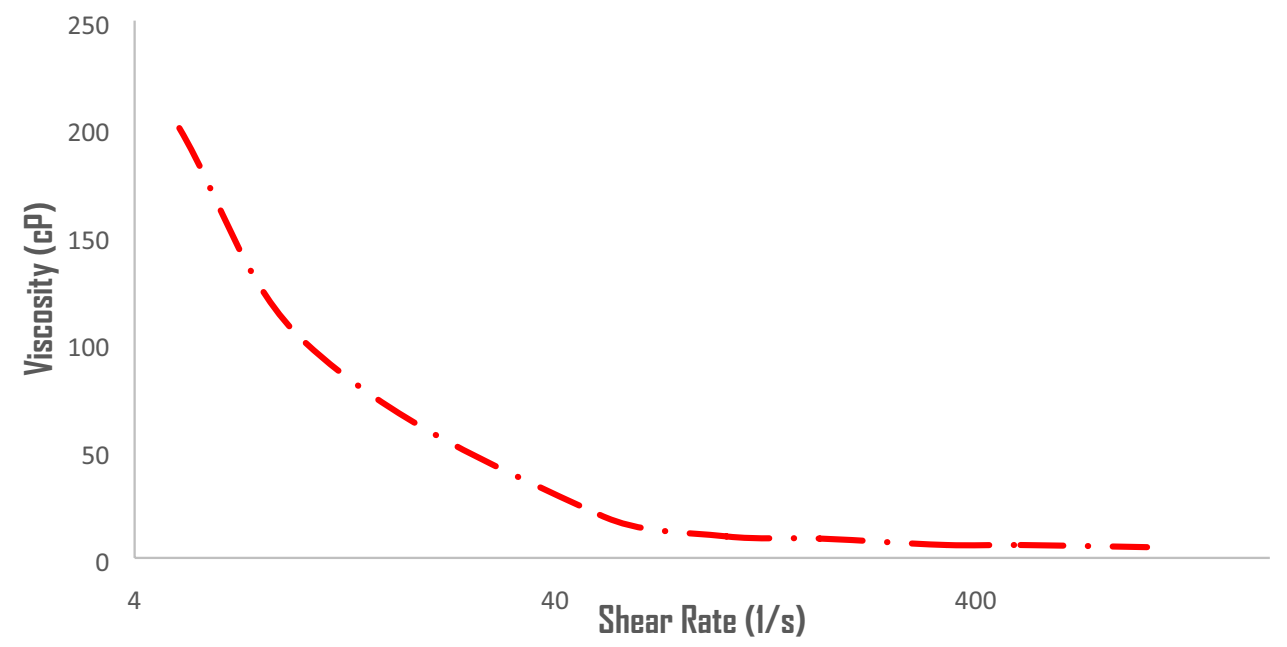


Fig. 5 Rheogram of the banana peel-derived polymer solution at different concentrations
Fig. 6 Rheogram of the mango kernel-derived polymer solution at different concentrations
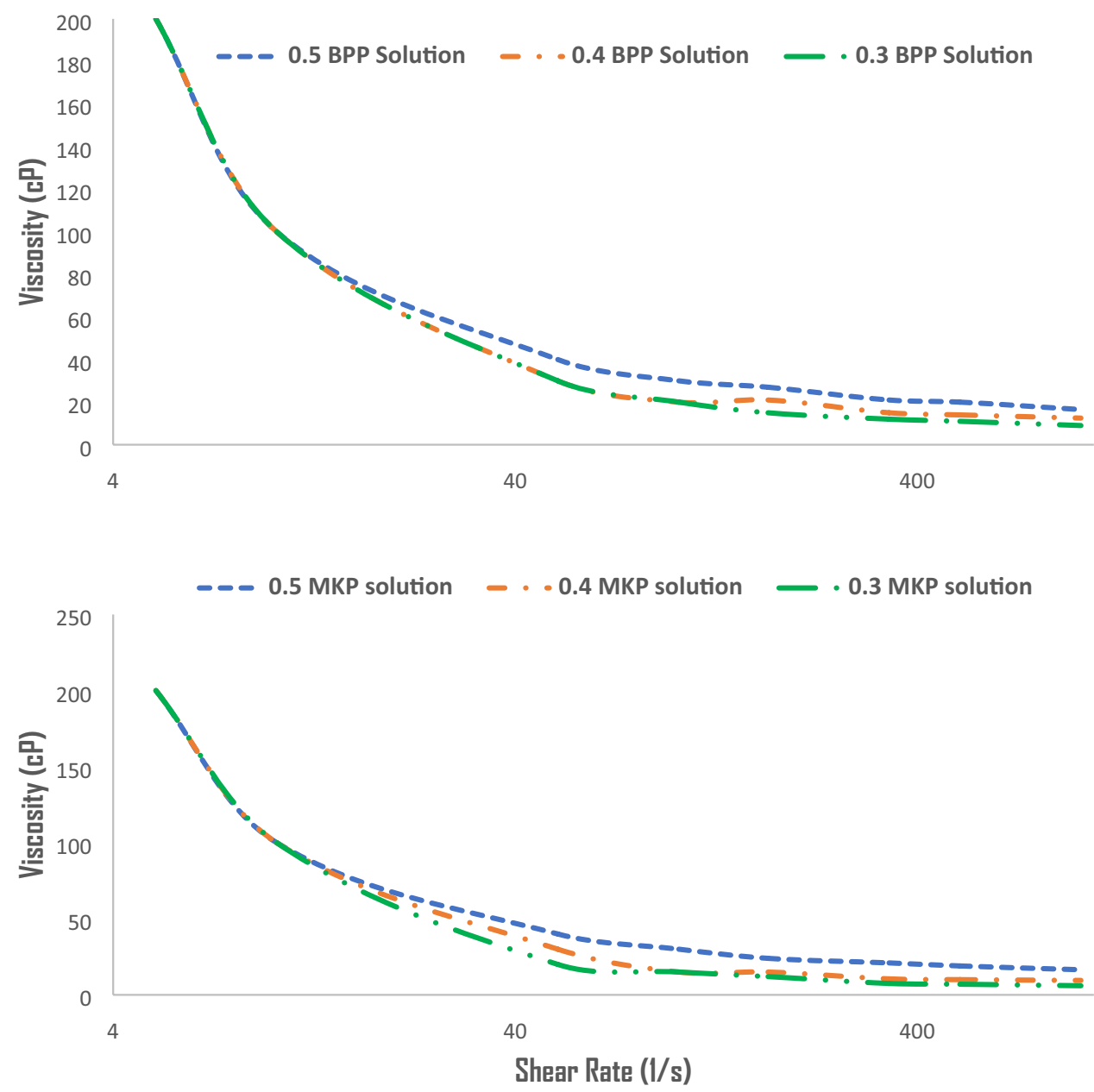

compared to banana peel-derived polymers. Although both polymers exhibited a shear thinning behavior, the mango kernel-derived polymer solutions show greater dependence of viscosity on the shear rate at higher concentration. The viscosity behavior of the higher concentration polymers is expected since in high concentrations, the number of polymer molecules in solution is expected to be higher resulting into better interaction in terms of entanglement of particles and/or cross-linking (Sarsenbekuly et al. 2017; Stavland et al. 2010, Olabode et al. 2020). During flooding, the injection rate is synonymous to the polymer solution shear rate, the injection rate will change as the fluid moves from the wellbore to deep within the reservoir in tandem is the polymer solution viscosity. This implies that the higher concentration of the mango-derived polymer solution is expected to exhibit better injectivity in terms of viscosity owing to its superior shear stress to shear rate relationship compared to banana- derived polymer solution.

\section{Oil recovery}

A total of six (6) core samples were used for the enhanced oil recovery applications, 18 flooding runs were conducted. Six (6) water flooding tests, six (6) mango kernel-derived polymer flooding tests and six (6) banana peel-derived polymer flooding tests were conducted. In each of the runs, waterflooding was first initiated followed by different concentrations of the two polymer solutions formulated.

Table 4 summarizes the initial saturation profiles of the core samples used, while Table 2 gives the petrophysical properties of the cores. Figures 7 and 9 present the volume of oil recovered from the sandstone core sample as a function of time for both mango kernel-derived polymer and banana peel-derived polymer flooding. Figures 8 and 10 show the percentage oil recovery against pore volume polymer solution injected for both mango kernel-derived polymer solutions and banana peel-derived polymer solutions, respectively. Irreducible water saturation and initial oil saturation conditions were achieved and measured after oil injection process. The first step of oil recovery test was conducted via conventional waterflooding and sustained until no trace 
Table 4 Saturation profile

\begin{tabular}{lcccccc}
\hline Parameters & Core sample 1 & Core sample 2 & Core sample 3 & Core sample 4 & Core sample 5 & Core sample 6 \\
\hline Pore volume (cc) & 17.90 & 16.40 & 19.00 & 9.00 & 10.90 & 11.50 \\
Volume of water expelled (cc) & 17.00 & 16.00 & 16.00 & 7.00 & 10.00 & 11.00 \\
Oil in place (cc) & 17.00 & 16.00 & 16.00 & 7.00 & 10.00 & 11.00 \\
Volume of connate water (cc) & 0.900 & 0.40 & 3.00 & 2.00 & 0.90 & 0.92 \\
So (v/v) & 0.95 & 0.98 & 0.84 & 0.22 & 0.08 & 0.96 \\
Swc (v/v) & 0.05 & 0.02 & 0.16 & 3.00 & 3.00 & 3.05 \\
Injection rate (cc/min) & 3.00 & 3.00 & 3.00 & & & 3.00 \\
\hline
\end{tabular}

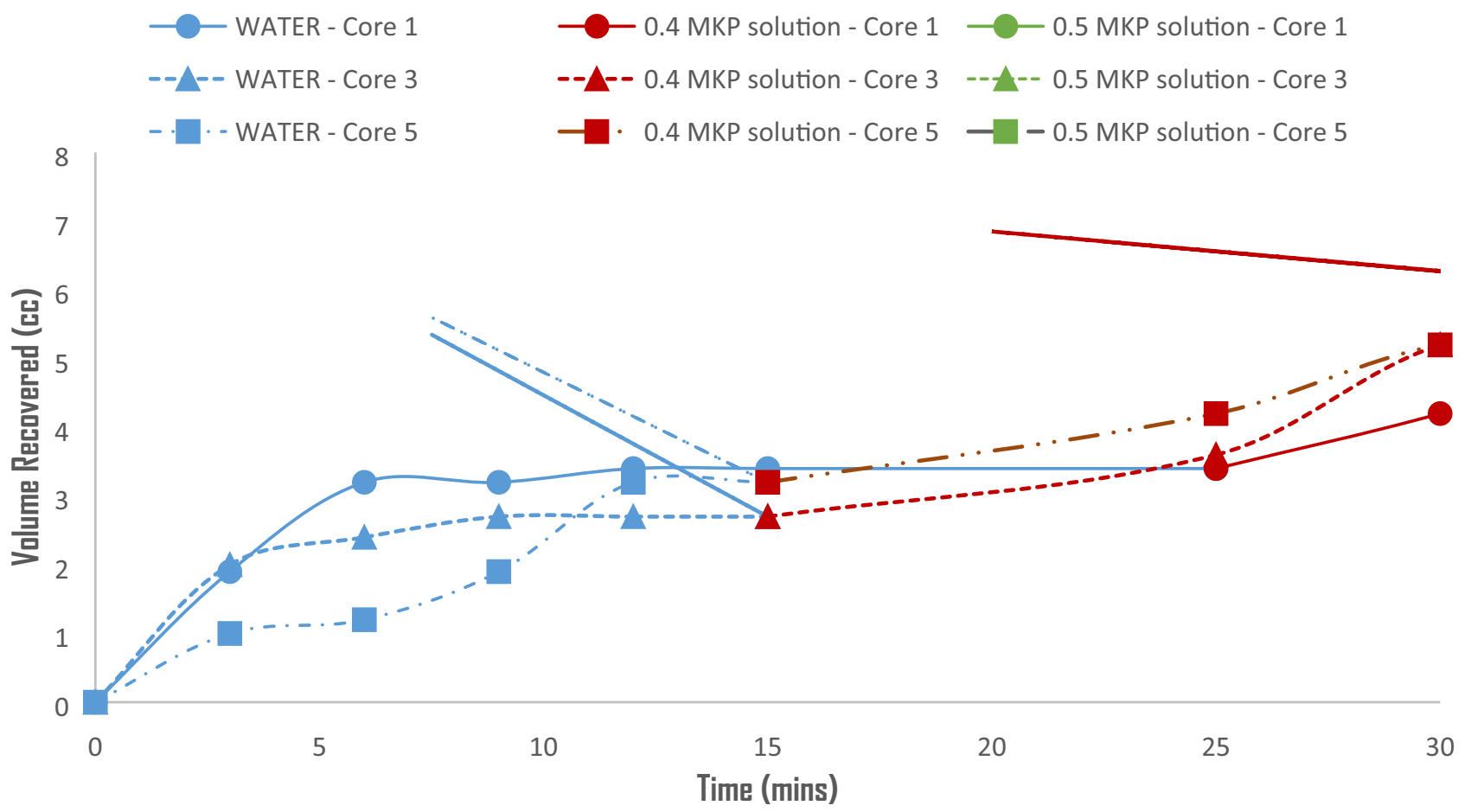

Fig. 7 Oil recovery performance evaluation for the different polymer solutions-derived from mango Kernel

of oil crude was noticed in the effluent. Subsequently, test to ascertain the suitability of the mango kernel and banana peel-derived polymers for enhanced oil recovery in terms of improving the sweep efficiency of the displacing fluid (by altering its mobility) was conducted. Figure 7 displays the performance of mango-derived polymer solutions and conventional waterflooding on cores 1,3 and 5 , in terms of incremental oil produced as a function of pore volume of polymer injected. All the mango kernel-derived polymer solutions (0.4 MKP and 0.5 MKP) show similar behavior; the injection of polymer and subsequent flooding of the oil in place results into a sharp increase in oil recovery (Figs. 7 and 8) that slowly peaked until a new concentration of polymer solution was introduced.

\section{Enhanced oil recovery performance of Mango kernel-derived polymer solutions}

Generally, from Fig. 8, conventional waterflooding was able to recover between 16.2 and 32 percent of the oil in place after an average of 3.6 pore volume water had been injected across the three (3) core samples used (Cores 1, 3 and 5). This is typical of conventional waterflooding process. After the mobility of the conventional water was altered by the introduction of $0.4 \mathrm{wt} \%$ mango kernel-derived polymer ( 0.4 MKP) solution, a rapid rise in oil recovery was experienced with an average percentage increase in recovery of about $40.6 \%$ across the three (3) core samples. $0.5 \mathrm{wt} \%$ mango kernel-derived polymer solution (0.5 MKP) demonstrates average percentage increase in recovery after waterflood of about $50.8 \%$ after an average of $4.8 \mathrm{cc}$ pore volume of 


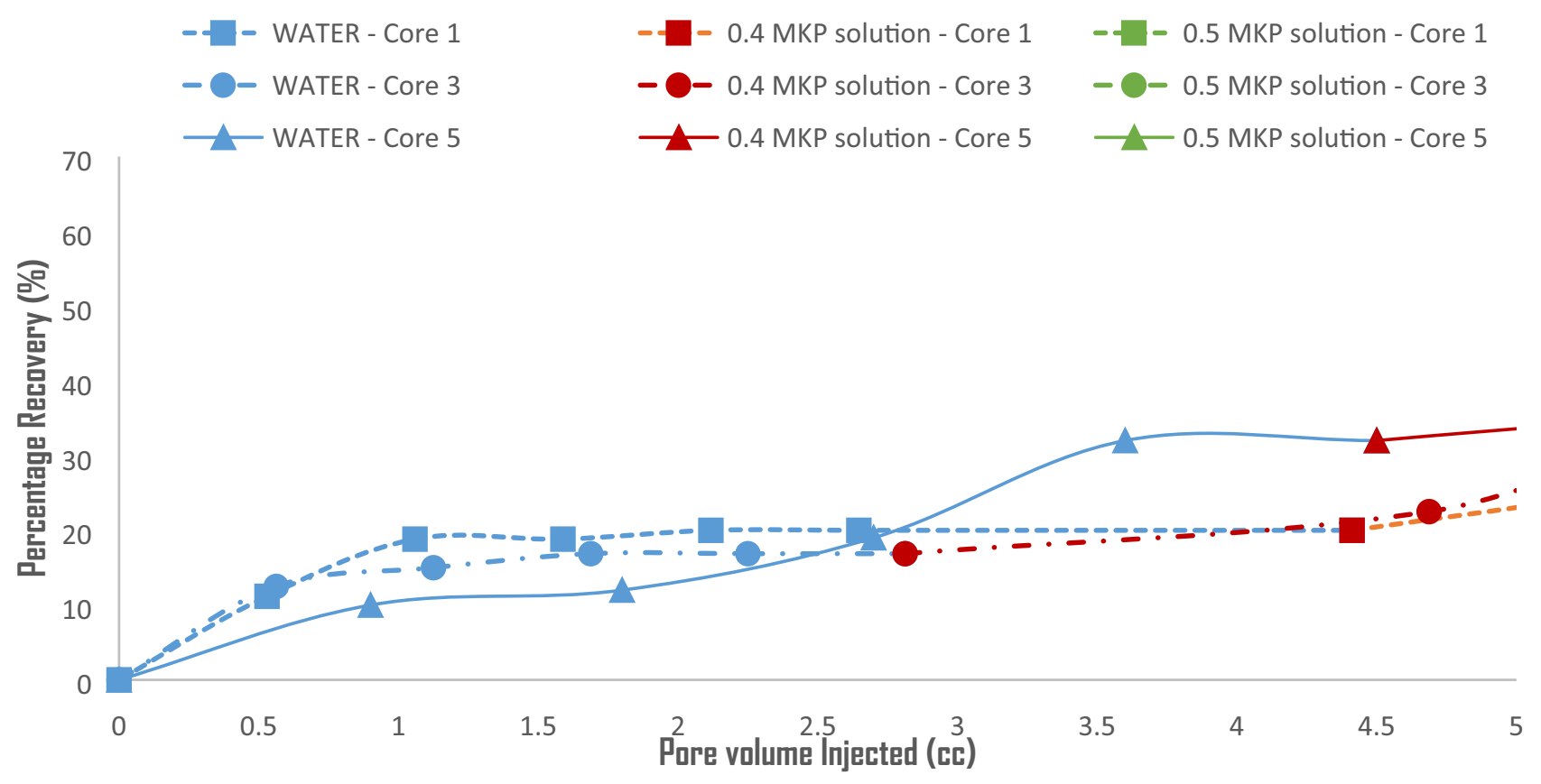

Fig. 8 Percentage recovery against pore volume injected for mango kernel- derived polymer solutions

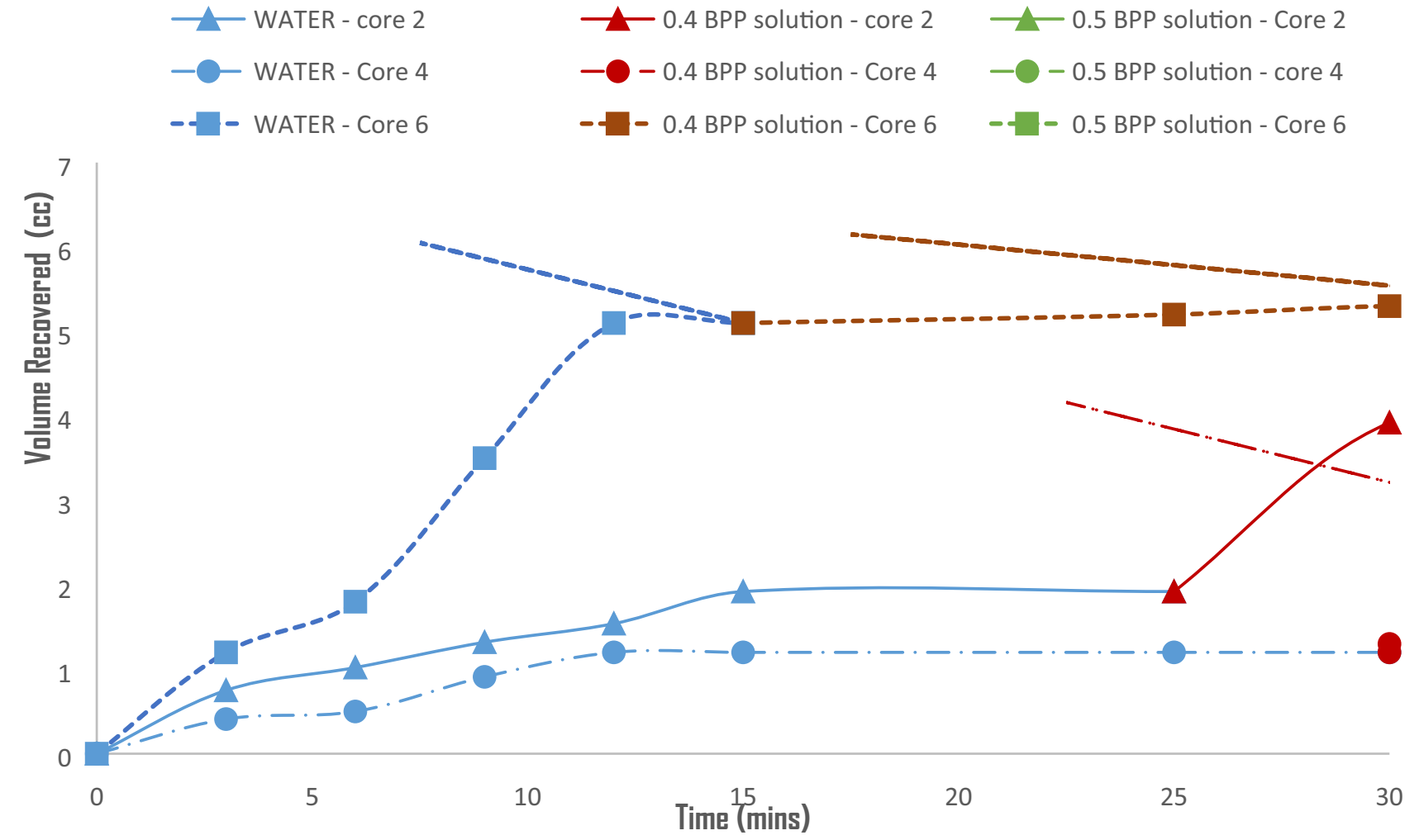

Fig. 9 Oil recovery performance evaluation for the different polymer solutions derived from banana peel 


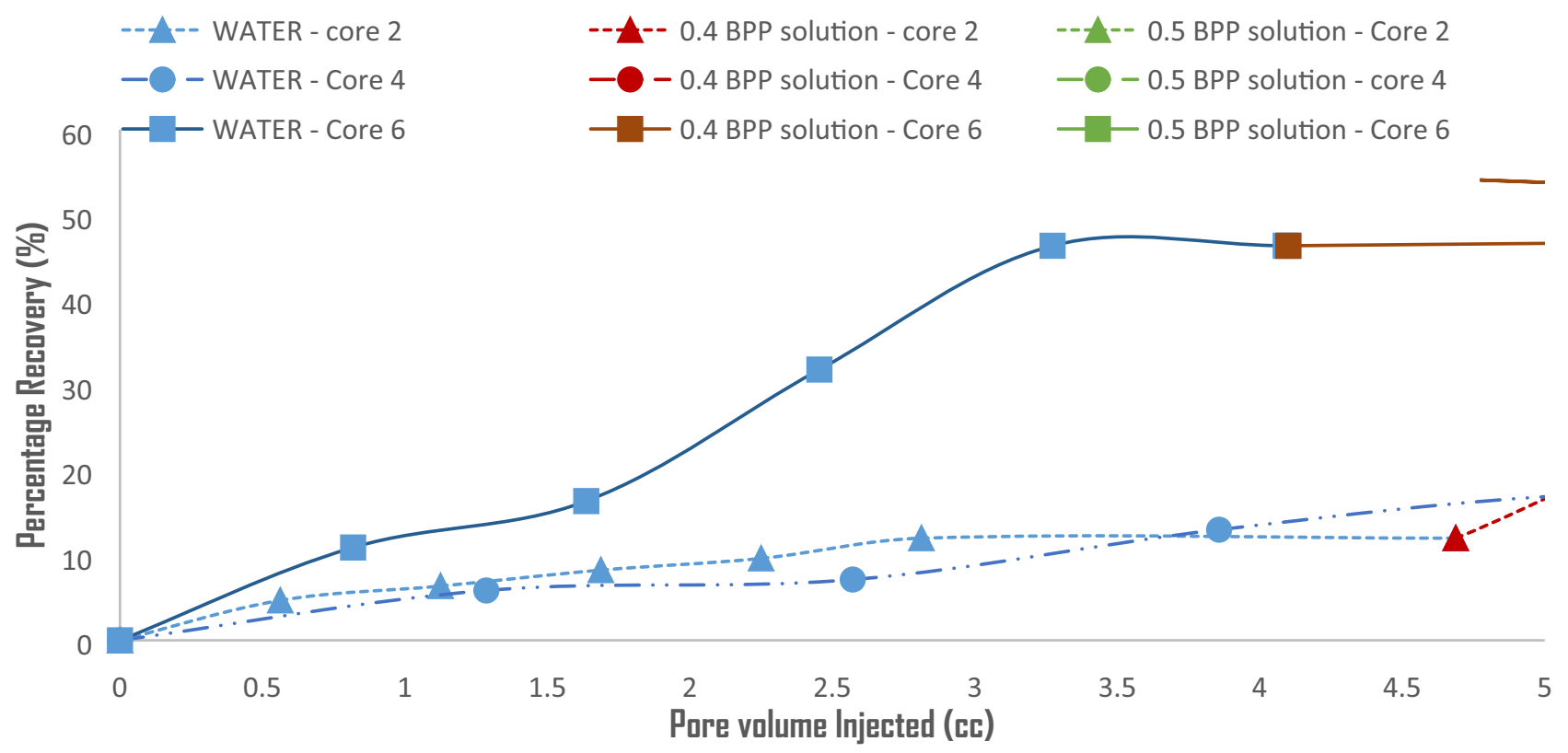

Fig. 10 Percentage recovery against pore volume injected for banana peel- derived polymer solutions

$0.5 \mathrm{wt} \%$ mango kernel-derived polymer solution had been injected.

\section{Enhanced oil recovery performance of banana peel-derived polymer solutions}

Figures 9 and 10 represent the incremental oil recoveries in terms of percentage oil in place and volume recovered via flooding tests conducted with conventional water, $0.4 \mathrm{wt} \%$ and $0.5 \mathrm{wt} \%$ banana peel-derived polymers, respectively, across three (3) cores (cores 2, 4 and 6). Similar trends as observed in mango kernel-derived polymer solution in terms of volume recovered and percentage recoveries after waterflood was observed in the flooding tests conducted with banana peel-derived polymer solutions except that comparatively low recoveries were observed in the tests with banana peel polymers compared with mango kernel polymer solutions. Average percentage incremental oil was 30.9 and 39.3 for tests conducted with $0.4 \mathrm{wt} \%$ and $0.5 \mathrm{wt} \%$ banana peelderived polymer solutions, respectively, across the three (3) core samples used. The varying incremental oil recoveries observed across the different core samples used could be attributed to the difference in their petrophysical properties, while the superior enhanced oil recovery performances (Table 5) demonstrated by the mango kernel-derived polymers can be said to be due to its higher carbohydrate content

Table 5 Enhanced oil recovery performance of the formulated polymers

\begin{tabular}{|c|c|c|c|c|c|c|}
\hline Core plug & $\begin{array}{l}\text { Polymer } \\
\text { type }\end{array}$ & $\begin{array}{l}\text { Permeability } \\
(\mathrm{mD})\end{array}$ & $\begin{array}{l}\text { Initial oil } \\
\text { in place } \\
(\%)\end{array}$ & $\begin{array}{l}\text { Percentage recovery } \\
\text { after water flood }(\%)\end{array}$ & $\begin{array}{l}\text { Percentage recovery } \\
\text { after } 0.4 \text { wt } \% \text { polymer } \\
\text { solution } \\
(\%)\end{array}$ & $\begin{array}{l}\text { Percentage recovery after } \\
0.5 \mathrm{wt} \% \text { polymer Solution } \\
(\%)\end{array}$ \\
\hline Core 6 & $\begin{array}{l}\text { Banana peel-derived } \\
\text { polymer }\end{array}$ & 97 & 96.9 & 16.2 & 48.2 & 53.6 \\
\hline Core 5 & $\begin{array}{l}\text { Mango kernel-derived } \\
\text { polymer }\end{array}$ & 92 & 91.7 & 32.0 & 54.0 & 62.0 \\
\hline Core 4 & $\begin{array}{l}\text { Banana peel-derived } \\
\text { polymer }\end{array}$ & 130 & 77.8 & 17.1 & 18.9 & 22.4 \\
\hline Core 3 & $\begin{array}{l}\text { Mango kernel-derived } \\
\text { polymer }\end{array}$ & 184 & 84.2 & 16.2 & 35.6 & 46.8 \\
\hline Core 2 & $\begin{array}{l}\text { Banana peel-derived } \\
\text { polymer }\end{array}$ & 180 & 97.5 & 12.0 & 25.6 & 38.8 \\
\hline Core 1 & $\begin{array}{l}\text { Mango kernel-derived } \\
\text { polymer }\end{array}$ & 192 & 94.9 & 20.0 & 31.8 & 43.5 \\
\hline
\end{tabular}


(76.84\%) compared with banana peel (59.0\%). The incremental oil recoveries could not have been possible without the introduction of the polymer flooding. These experimental results demonstrate the potential suitability of mango kernel and banana peel-derived polymer for enhanced oil recovery applications.

\section{Conclusions}

The performance of two bio-derived polymers (mango kernel and banana peel) as mobility control polymers in enhanced oil recovery applications was evaluated. The bio-based polymers were extracted from mango kernel and banana peel wastes, respectively. The polymers were modified via acid hydrolysis to reduce the amylopectin (branched chains) contents of the polymer. The improvement in viscosity was demonstrated in the difference in rheological behavior of the formulated polymer solutions before and after modification. Their suitability for enhanced oil recovery was evaluated via core flooding tests. The results of the polymer flooding tests showed that the formulated polymers exhibited encouraging potentials for enhanced oil recovery abilities. The major conclusions relating to the study objectives and results are highlighted as follows:

i. The biopolymer extraction method from mango kernel and banana peel was very effective as demonstrated in the improved viscosity of water upon introduction of polymers as seen in the rheological properties and core flooding after conventional waterflood.

ii. Banana peel waste-derived polymer solution recovered an incremental oil between 30.9 and $39.3 \%$ of the initial oil place after waterflood, while mango kernelderived polymer solutions exhibited superior recovery capacity with improved recovery between 40.6 and $50.8 \%$ of the initial oil in place after waterflood and between 16.2 and $32 \%$ of initial oil place were recovered by conventional waterflood experiment.

iii. The improvement in the oil recovery by the extracted polymers was due to reduced mobility to water by the introduction of polymer molecules into water in the sandstone cores. This contributed to the displacement of trapped oil by the displacing polymer solutions.

iv. Banana and mango-derived biopolymer has demonstrated high efficiency for enhancing recovery of oil in sandstone formation and they serve as a potential soluble biopolymer for augmenting waterflooding and keep our environment safe. However, laboratory study for determining interfacial tension, wettability and contact angle is recommended to further affirm their mechanism of oil recovery from the porous media.

\section{Suggestions for future work}

The findings in this study are only limited to the standard laboratory conditions. Effects of salinity and temperature at extreme conditions are essential factors to be considered, especially on the biopolymer's stability at reservoir conditions. Further studies should investigate how to ensure the stability of these polymers at reservoir conditions.

Funding The authors received no specific funding for this work.

\section{Declarations}

Conflict of interest The authors declare that they have no conflict of interest.

Open Access This article is licensed under a Creative Commons Attribution 4.0 International License, which permits use, sharing, adaptation, distribution and reproduction in any medium or format, as long as you give appropriate credit to the original author(s) and the source, provide a link to the Creative Commons licence, and indicate if changes were made. The images or other third party material in this article are included in the article's Creative Commons licence, unless indicated otherwise in a credit line to the material. If material is not included in the article's Creative Commons licence and your intended use is not permitted by statutory regulation or exceeds the permitted use, you will need to obtain permission directly from the copyright holder. To view a copy of this licence, visit http://creativecommons.org/licenses/by/4.0/.

\section{References}

Adesina F, Abiodun A, Olugbenga Fa (2014) A new analytical model for developing fractional flow curve using production data. $\mathrm{J}$ Chem Petroleum Eng 48(2):81-90

Adewole JK, Muritala KB (2019) Some applications of natural polymeric materials in oilfield operations: a review. J Petroleum Explor Prod Technol 9(3):2297-2307

Ali JA, Kolo K, Manshad AK, Stephen KD (2019) Potential application of low-salinity polymeric-nanofluid in carbonate oil reservoirs: IFT reduction, wettability alteration, rheology and emulsification characteristics. J Mol Liq 284:735-747

Altemimi AB (2018) Extraction and optimization of potato starch and its application as a stabilizer in yogurt manufacturing. Foods 7(2): 14

Anhwange BA, Ugye TJ, Nyiaatagher TD (2009) Chemical composition of Musa sapientum (banana) peels. Electron J Environ Agric Food Chem 8(6):437-442

Fadairo A, Adeyemi G, Onyema O, Adesina A (2019) Formulation of bio-waste derived polymer and its application in enhanced oil recovery. In SPE Nigeria Annual International Conference and Exhibition. Society of Petroleum Engineers

Green DW, Willhite GP (1998). Enhanced oil recovery (Vol. 6, pp. 143-154). Richardson, TX: Henry L. Doherty Memorial Fund of AIME, Society of Petroleum Engineers

Hatzignatiou DG, Giske NH, Stavland A (2016) Polymers and polymerbased gelants for improved oil recovery and water control applications in naturally fractured chalk formations. In SPE Bergen one-day seminar. Society of Petroleum Engineers 
Hatzignatiou DG, Giske NH, Stavland A (2018) Polymers and polymer-based gelants for improved oil recovery and water control in naturally fractured chalk formations. Chem Eng Sci 187:302-317

Kumar S, Mandal A (2017) Rheological properties and performance evaluation of synthesized anionic polymeric surfactant for its application in enhanced oil recovery. Polymer 120:30-42

Lake LW, Johns R, Rossen B, Pope G (2014) Fundamentals of enhanced oil recovery. Society of Pet Engineers, Richardson TX

Mishra S, Bera A, Mandal A (2014) Effect of polymer adsorption on permeability reduction in enhanced oil recovery. J Pet Eng. https:// doi.org/10.1155/2014/395857

Muazu J, Musa H, Isah AB, Bhatia PG, Tom GM (2011) Extraction and characterization of Kaffir potato starch: a potential source of pharmaceutical raw material. J Nat Prod Plant Resour 1(2):41-49

Ogunkunle T, Fadairo A, Ling K, Rasouli V, Chukwuma O, Oladepo A (2020) Microbial derived biosurfactant using neem oil as substrate and its suitability for enhanced oil recovery. J Pet Explor Prod 11(2):627-638

Olabode O, Ojo T, Oguntade T, Oduwole D (2020) Recovery potential of biopolymer (BP) formulation from Solanum tuberosum (waste) starch for enhancing recovery from oil reservoirs. Energy Rep 6:1448-1455

Oladepo David A, Churchill A, Fadairo Adesina S, Tope O (2017) Evaluation of different wag optimization and secondary recovery techniques in a stratified reservoir. Int J Appl Eng Res 12(20):9259-9270

Pope GA (2007) Overview of chemical EOR. In Casper EOR workshop. The University of Texas at Austin Austin, TX

Raffa P, Wever DAZ, Picchioni F, Broekhuis AA (2015) Polymeric surfactants: synthesis, properties, and links to applications. Chem Rev 115(16):8504-8563

Riahinezhad M, Romero-Zerón L, McManus N, Penlidis A (2017) Evaluating the performance of tailor-made water-soluble copolymers for enhanced oil recovery polymer flooding applications. Fuel 203:269-278

Riahinezhad M, Romero-Zerón L, McManus N, Penlidis A (2017) Design of tailor-made water-soluble copolymers for enhanced oil recovery polymer flooding applications. Macromol React Eng. https://doi.org/10.1002/mren.201600020

Sarsenbekuly B, Kang W, Yang H, Zhao B, Aidarova S, Yu B, Issakhov M (2017) Evaluation of rheological properties of a novel thermoviscosifying functional polymer for enhanced oil recovery. Colloids Surf A 532:405-410

Singh J, Kaushik N, Biswas S (2014) Biodegradable polymers-technology and business opportunities. Popul Plast Packag 59(3):21-31

Stavland A, Jonsbraten, H, Lohne A, Moen A, Giske NH (2010) Polymer flooding-flow properties in porous media versus rheological parameters. In SPE EUROPEC/EAGE Annual Conference and Exhibition. Society of Petroleum Engineers

Sydansk RD (2007) Polymers gels foams and resins. In: Holstein ED (ed) Petroleum engineering handbook. Society of Petroleum Engineers, Richardson

Torres-León C, Rojas R, Contreras-Esquivel JC, Serna-Cock L, Belmares-Cerda RE, Aguilar CN (2016) Mango seed: functional and nutritional properties. Trends Food Sci Technol 55:109-117

Zhang H, Hou H, Liu P, Wang W, Dong H (2019) Effects of acid hydrolysis on the physicochemical properties of pea starch and its film forming capacity. Food Hydrocolloids 87:173-179

Publisher's Note Springer Nature remains neutral with regard to jurisdictional claims in published maps and institutional affiliations. 